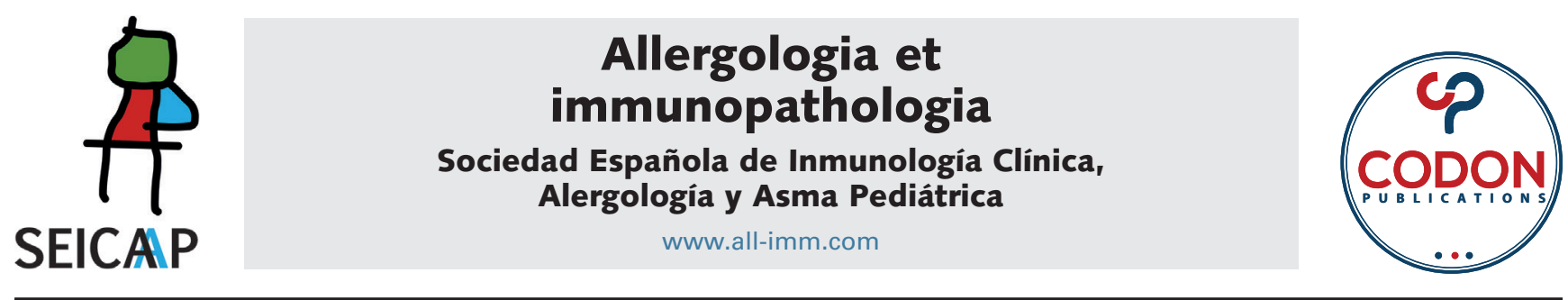

ORIGINAL ARTICLE

OPEN ACCESS @(1) (;)

\title{
Component resolved diagnosis of egg yolk is an indispensable part of egg allergy
}

\author{
Huang Lunhui ${ }^{\mathrm{a}, \mathrm{b}}$, Shao Yanhong ${ }^{\mathrm{b}}$, Li Shaoshenc, Bao Huijing ${ }^{\mathrm{d}}$, Liu Yunde ${ }^{\mathrm{b} *}$, Li Huiqiang ${ }^{\mathrm{b} *}$
}

a State Key Laboratory of Experimental Hematology, National Clinical Research Center for Blood Diseases, Institute of Hematology \& Blood Diseases Hospital, Chinese Academy of Medical Sciences \& Peking Union Medical College, Tianjin, China

${ }^{b}$ School of Medical Laboratory, Tianjin Medical University, Tianjin, China

'Academy of Traditional Chinese Medicine Affiliated Hospital, Hongqiao District, Tianjin, China

${ }^{d}$ The Integrative Medical Diagnosis Laboratory, Tianjin Nankai Hospital, Tianjin, China

Received 3 April 2020, Accepted 15 June 2020

Available online 1 March 2021

\author{
KEYWORDS \\ egg white; \\ egg yolk; \\ specific lgE; \\ component resolved \\ diagnostic; \\ area under curve
}

\begin{abstract}
Introduction and objectives: It was urgent to explain the role of egg yolk allergen sensitization to the egg allergic population and we would evaluate the diagnostic value of allergen components in whole eggs, including egg white and egg yolk.

Materials and methods: Firstly, we collected 99 positive and 21 negative sera against egg allergy. Then we used modified enzyme linked immunosorbent assay (ELISA) to survey specific IgE (slgE) to all-proven and single component in eggs, Ovomucoid (Gal d 1), Ovalbumin (Gal d 2), Ovotransferrin (Gal d 3), Lysozyme C (Gal d 4), Serum Albumin (Gal d 5), and YGP42(Gal d 6) in allergic and non-allergic populations. Last but not least, we studied the slgE reactivities to egg allergen components by receiver operating characteristic (ROC) analysis.

Results: Among egg-allergic individuals, nearly $10 \%$ were sensitized to five of six egg allergen components, and the cross-reaction frequency between two egg yolk allergens with Gal d 1 was about $30 \%$ in the groups diagnosed with egg allergy or non-allergy. The best component-combination diagnosis in egg allergy of Gal d 1+ Gal d 6 demonstrated the largest area under curve (AUC) of 0.994.

Conclusions: Our results suggested that there were individual differences in allergenicity of different egg allergen components, especially in the samples negative to egg allergy diagnosed but sensitive to egg yolk components. It was indicated that component resolved diagnosis of egg yolk improved the value for egg allergy management indispensably.

(c) 2021 Codon Publications. Published by Codon Publications.
\end{abstract}

Corresponding authors: Liu Yunde and Li Luiqiang, School of Medical Laboratory, Tianjin Medical University, Tianjin, China. Email address: liuyunde5@126.com and lihuiqiang20@163.com 


\section{Introduction}

More than 1 billion people worldwide suffer from allergic diseases, with the prevalence set to reach up to 4 billion people in the 2050s. ' Hen's egg allergy (HEA) is the second most common food allergy, and affects up to $9 \%$ of babies while other major food allergies include peanut (3\%) and sesame $(0.8 \%) .2,3$ Food allergy directly affects the quality of life of patients and their families and increases children's vulnerability to society ostracism. ${ }^{4}$ While allergies occurs, patients tend to quickly manifest nausea, abdominal pain, mild urticaria and/or vomiting, more severe hypotension, cardiovascular collagenase, respiratory distress, and/or death. ${ }^{3,5}$

While hen's eggs are a versatile ingredient for use in many foods and a variety of manufactured products, it may be hard to avoid eggs. ${ }^{6}$ In general, clinical methods used to diagnose food allergy are skin prick test (SPT) and detection of food-specific immunoglobulin $E$ levels in patients. However, the use of raw extracts of allergens, a mixture of allergic and non-allergic ingredients, reduce the reliability of these tests. ${ }^{7}$ Patient and environmental factors will substantially influence the interpretation of lgE sensitization test results. ${ }^{8}$ In order to improve diagnostic accuracy, component resolved diagnosis (CRD) has been introduced into routine clinical practice. ${ }^{9,10}$ Recently, some clinical cohort studies have suggested that egg allergen CRD may be useful. ${ }^{11-14}$

Egg allergens are concentrated in egg yolk and egg white. Egg white allergens, ovomucoid (OVM; Gal d 1, approximately 11\%), ovalbumin (OVA; Gal d 2, approximately $54 \%$ ), ovotransferrin (Gal d 3, approximately $12 \%$ ), and lysozyme (Gal d 4, approximately 3\%) have been identified as the major allergens causing egg allergy. ${ }^{15}$ However, according to the results of the oral food challenge (OFC), 9.1\% of the children with egg allergy also showed a positive reaction to the heated yolk lightly contained with egg white. ${ }^{16}$ In fact, egg yolk allergy (EYA) has been gaining more and more attention. In a recent study, the diagnosis of egg yolk allergy in children clearly confirmed the allergens. Serum albumin (Gal d 5) and YGP42 (Gal d 6) were the main allergens in egg yolk. ${ }^{17,18}$ Recent studies have confirmed that children diagnosed with egg allergy had sensitization to egg yolk. ${ }^{19-21}$ Furthermore, the fine differentiation of egg allergy, its yolk resistance, and its egg yolk reactive with slight egg white contamination can be used to predict the natural course of egg allergy in early childhood. ${ }^{16}$

Above all, there is little information about the egg yolk allergen components in egg allergy. Precise diagnosis of yolk and white allergies is crucial for even better regulation of egg allergies and avoidance of uncalled-for dietary restrictions. In this research, we carried out the analysis of the diagnostic value of the whole egg components in egg allergy. More importantly, we discovered that component resolved diagnostics of egg yolk would improve the diagnostic value of egg allergy.

\section{Materials and Methods}

\section{Patients and serum}

The diagnosis of egg allergy mediated by IgE is based on credible clinical cases, including egg intake, severe or acute reactions, and increased specific IgE levels (eggslgE > $0.35 \mathrm{kUA} / \mathrm{L}$ ) detected by the Immuno CAP System (Thermo Fisher Scientific, Sweden).The serum samples we collected were from Tianjin Children's Hospital and Academy of Traditional Chinese Medicine Affiliated Hospital, including 21 non-atopic controls and 99 allergic individuals.

\section{SIgE antibodies-detection against whole egg allergen components}

We employed a modified indirect enzyme-linked immunosorbent assay (Indirect-ELISA) for slgE antibodiesdetection against whole egg allergens. Briefly, Gal d 6 was prepared and preserved in our own laboratory and the others were obtained from Sigma-Aldrich Co. In the first place, $50 \mu \mathrm{g} / \mathrm{ml}$ of each component was prepared and dissolved in $0.05 \mathrm{M}$ carbonate buffer $(\mathrm{pH}$ 9.6). Next, every well was coated with $125 \mu$ l protein at room temperature for $4 \mathrm{~h}$ and then at $4{ }^{\circ} \mathrm{C}$ for $16 \mathrm{~h}$. On the following day, the wells were washed with Phosphate-buffered saline tween (PBST) containing $0.05 \%$ (v/v) Tween 20 on ELx50TM, Automatic Washing Machine(Bio Tek, USA), which was used for each step of cleaning. The plates were blocked with $200 \mu \mathrm{l}$ PBST composed of $2 \%$ polyvinyl alcohol (PVA) and $0.05 \%$ glycine overnight at $4{ }^{\circ} \mathrm{C}$. In addition, $100 \mu \mathrm{l}$ serum diluted $1: 10$ in PBST was added to the microtiter plate. After incubation for $2 \mathrm{~h}$ at $37{ }^{\circ} \mathrm{C}$, the ELISA plates were washed three times. Following $1 \mathrm{~h}$ incubation at $37{ }^{\circ} \mathrm{C}$, HRP-labelled anti-human IgE antibodies (diluted 1:1000 in PBST; Sigma-Aldrich, USA) were added to every well. They were then washed five times with PBST, with 3, 5', 5, 5' - tetramethylbenzidine. TMB chromogenic substrate. Finally, we tested the signal values at $450 \mathrm{~nm}$ (OD450) using Synergy2 Multimode Microplate Reader (Bio Tek, VT, USA). According to the indirect ELISA method established by us, the serum samples of healthy people were used as the control. Origin 7.0 statistical software was used to calculate the mean value and standard deviation of sample absorbance at $450 \mathrm{~nm}$.

Because the specific IgE cut-off values for each allergen are different, ${ }^{22}$ we have determined the cut-off values of Gal d 1, Gal d 2, Gal d 3, Gal d 4, Gal d 5, and Gal d 6 , respectively, by adding 2 SD to the average optical density value of 21 healthy individuals controls. The absorbance at $450 \mathrm{~nm}$ was read as the slgE level for each yolk component.

\section{Statistical analysis}

All statistical analyses were performed using GraphPad Prism Version6.0 Software. Wilcoxon matched-pairs test or Mann-Whitney test was performed to compare two groups. Two-tailed

$\mathrm{P}$-values were reported with the significance level set at 0.05 . $P \leq 0.05$ was considered statistically significant. To assess test performances, ROC analyses were performed on single component and combinant components. 

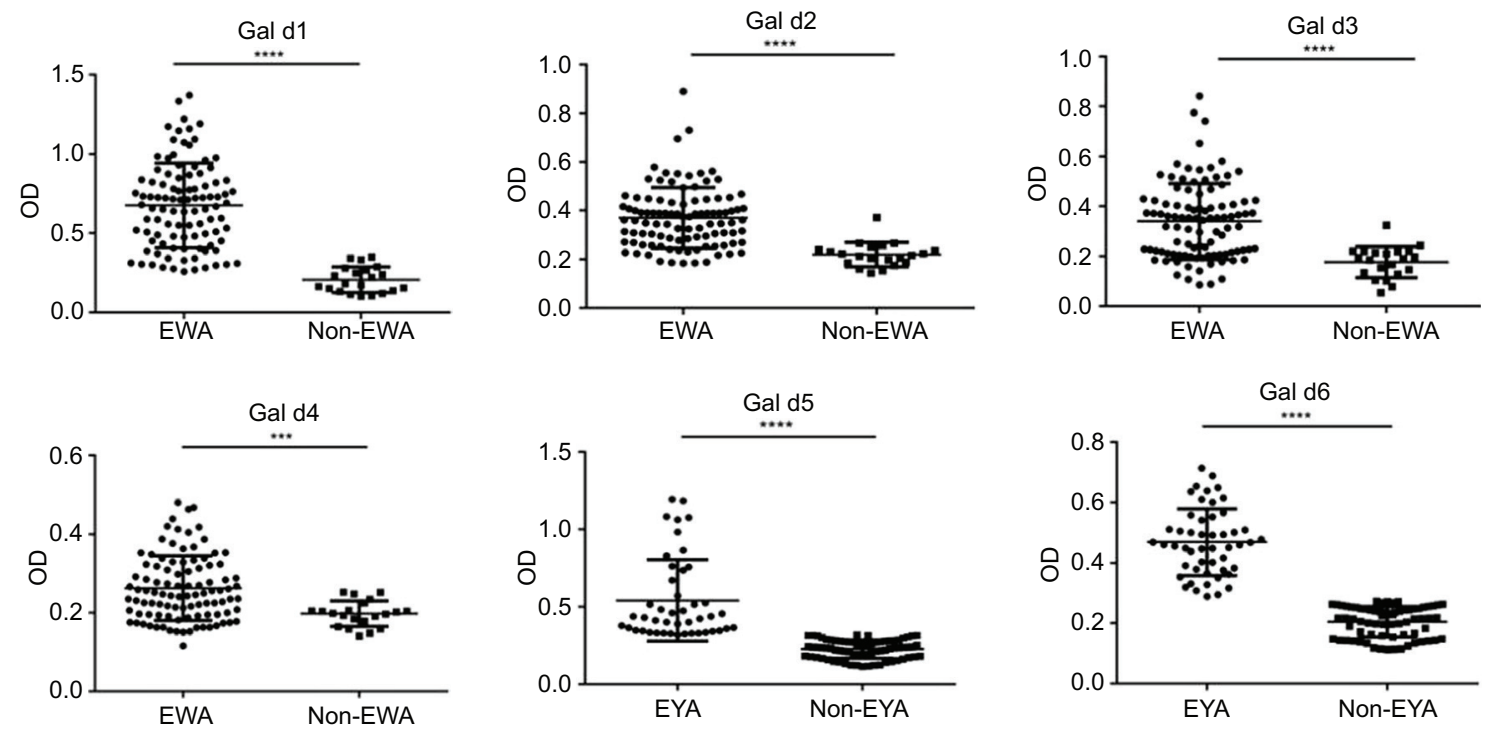

Figure 1 Comparison of serum slgE antibodies against whole egg allergen components.

\section{Results SlgE antibodies-detection against whole egg
allergen components}

Egg white allergy (EWA) and egg yolk allergy (EYA) are both part of human egg allergy (HEA). There was a significant difference in slgE level of diverse single component in each group (Figure 1). Compared with the non-EWA group, the average slgE antibodies level in EWA group was significantly higher against Gal d 1 (OD450 0.665 vs. 0.201), Gal d 2 (OD450 0.370 vs. 0.220), Gal d 3 (OD450 0.339 vs. 0.177), and Gal d 4 (OD450 0.262 vs. 0.197). We used the lowest average OD value of 21 cases as the negative value and $\mathrm{P} / \mathrm{N}$ greater than or equal to 2.1 as the positive value for re-grouping. SIgE antibodies level in EYA group was remarkably higher than that in the control group against Gal d 5 (OD450 0.541vs. 0.226), Gal d 6 (OD450 0.469 vs. 0.263).

\section{Outlines of slgE antibodies against egg allergen components in allergic group}

Table 1 presents the proportions of egg white and egg yolk allergen components against slgE antibodies respectively. Figure 2 shows that 79\% (78/99) had measurable slgE to Gal d 1; 68\% (67/99) had measurable slgE to Gal d 2; 58\% (57/99) had measurable slgE to Gal d 3; 44\% (44/99) had measurable slgE to Gal d 4; $38 \%$ (46/120) had measurable slgE to Gal d 5; 42\% (50/120) had measurable slgE to Gal d 6. Among the components of egg yolk allergen and egg white allergen, we sorted out their cross-proportion frequencies. The highest cross-reaction rate of Gal d 5 and Gal d 6 were with Gal d 1, respectively $33 \%$ and $36 \%$. Between the two egg yolk allergen components, the cross proportion was 18\% (Table 1).
Table 1 Cross proportions of egg yolk allergy with egg white allergy.

Gal d 1 Gal d 2 Gal d 3 Gal d 4 Gal d 5 Gal d 6

\begin{tabular}{rrrrrrr}
\hline Gal d 5 & $33 \%$ & $28 \%$ & $22 \%$ & $11 \%$ & $100 \%$ & $18 \%$ \\
Gal d 5 & $36 \%$ & $33 \%$ & $25 \%$ & $15 \%$ & $18 \%$ & $100 \%$ \\
\hline
\end{tabular}

\section{Frequencies of the number of allergens in the sensitized population}

The frequency distribution of six major allergen components in the whole egg in sensitized population has been measured in Figure 3. There were mostly egg allergic patients sensitized to more multiple components than to a single component. Most patients (28.32\%) were sensitive to four of six tested egg proteins; $9.7 \%$ of patients were sensitized to five of six egg allergen components. Diagnostic values of single egg white allergen component in EWA.

The diagnostic performance of IgE activity to every egg white component was analyzed by ROC. We compared the area under the curve (AUC) of different egg white allergen components. SIgE sensitized to Gal d 1 had the largest AUC and thus put on display the best diagnostic values in distinguishing the EWA from non-EWA groups. Additionally, we had comparable AUC values of the slgE to whole egg white allergen components, ranging from 0.76 to 0.977 (Figure 4).

\section{Diagnostic values of combinant components of egg components}

We selected Gal d 1 as the highest diagnostic value of the egg white allergens as part of the combinant diagnosis. Then we used ROC curve analysis to assess and compare 

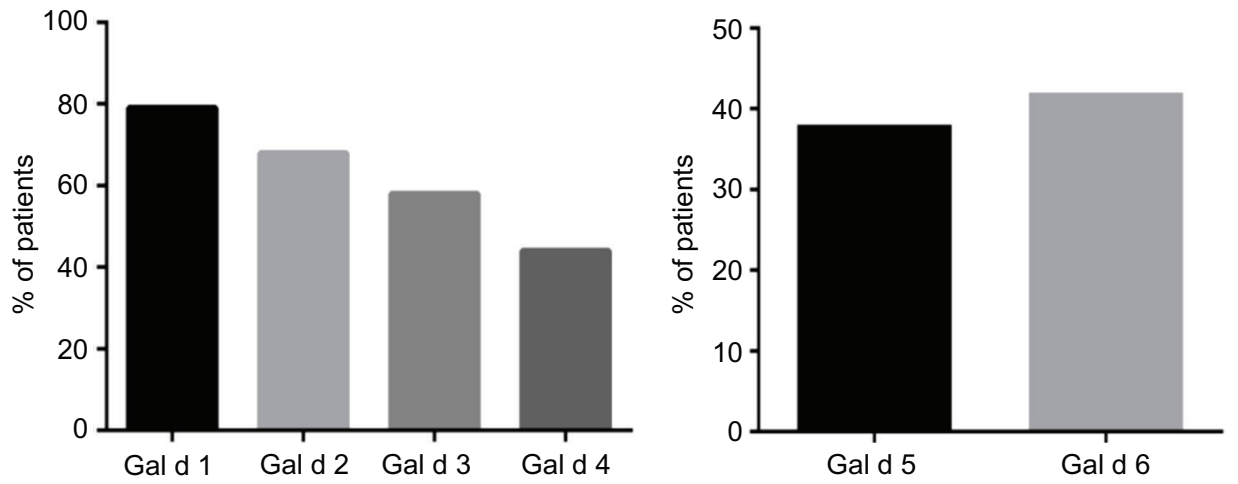

Figure 2 Distribution of egg allergen components in allergic group.

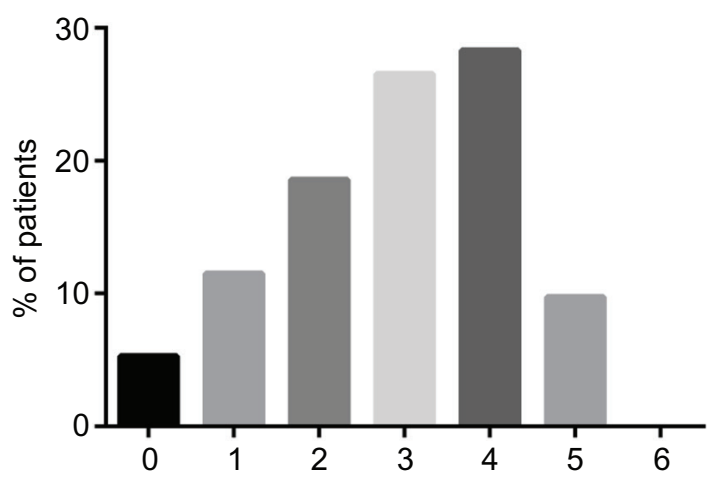

Figure 3 Comparison of the frequencies of different allergens in the sensitized population. 0-6, quantity of components detected in six components. the diagnostic value of slgE response to Gal d 1 with one or two egg yolk allergen components. The results suggested the AUC of combinant components was bigger than single Gal d 1, the highest diagnostic value of the egg white allergens. The combinant components Gald $1+$ Gald 6 had the highest AUC of 0.994 among all combinations. (Figure 5).

\section{Discussion}

Eggs have been identified as representing the lowest-cost source of nutrients. ${ }^{23}$ Egg proteins are distributed evenly between egg white and egg yolk, while lipids, vitamins, and minerals are essentially concentrated in egg yolk. ${ }^{24}$ Nutrition and health problems are emerging as egg consumption is increasing. Therefore, much more accurate diagnosis is urgently needed.
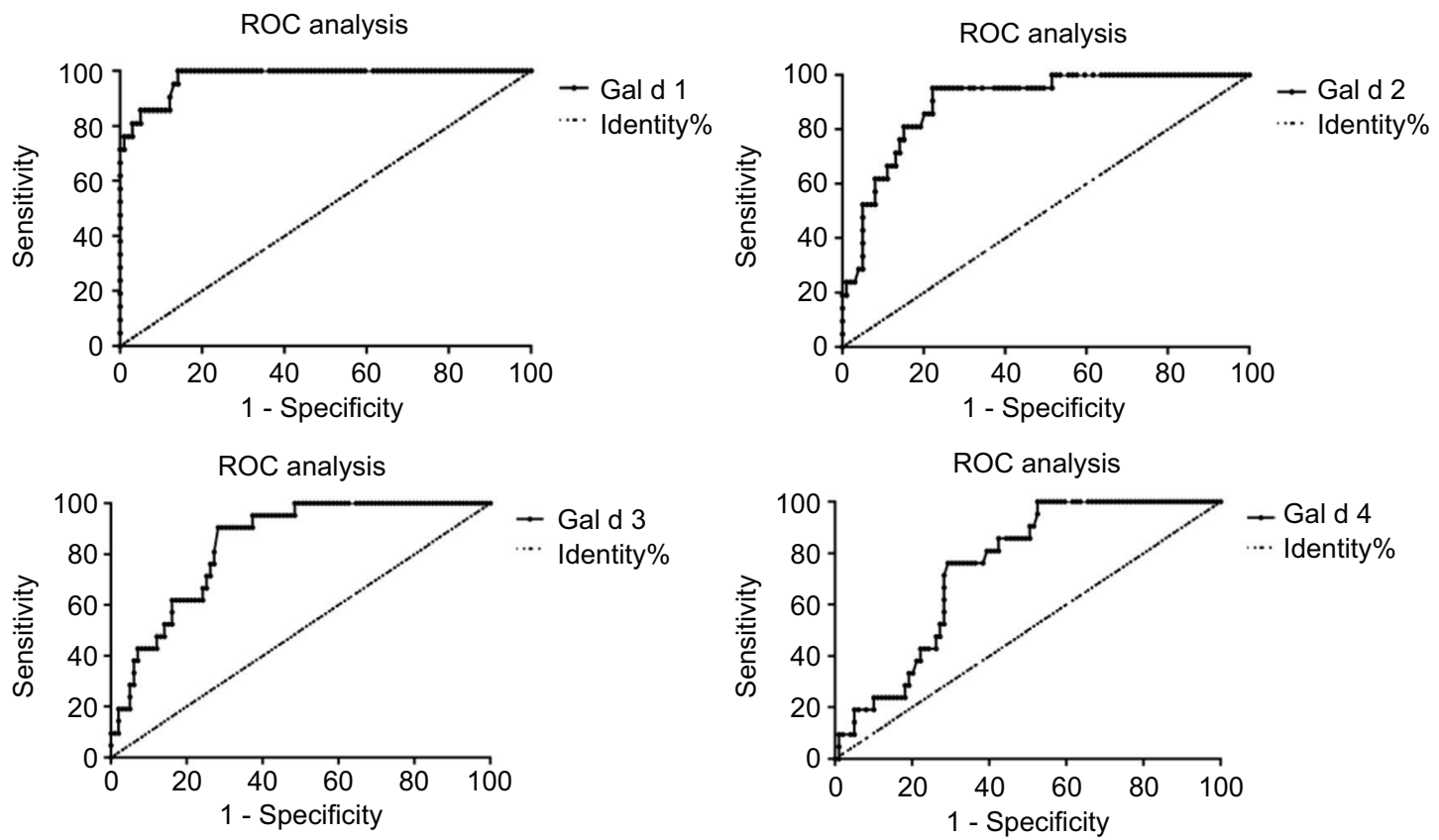

Figure 4 ROC analysis of slgE response to egg white allergen components. 


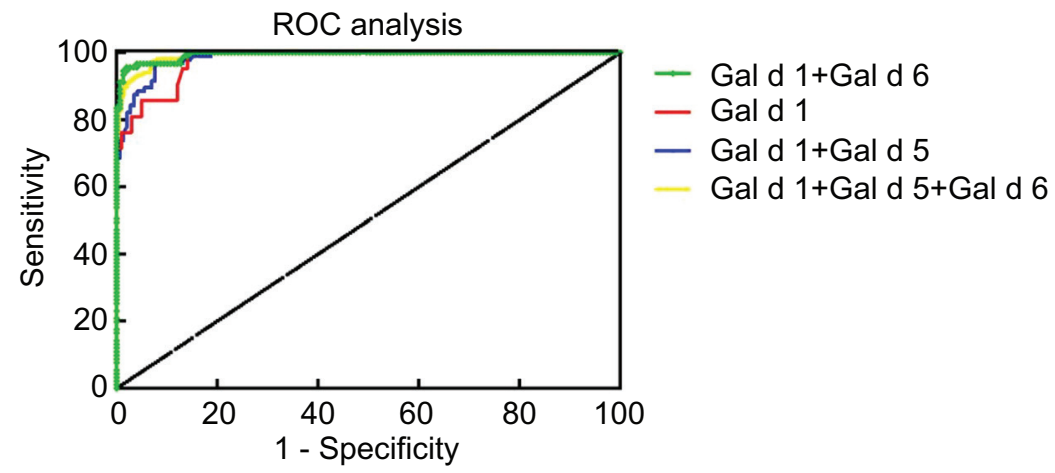

Figure 5 ROC analysis of slgE response to combined Gal d 1 with egg yolk allergen components.

The food challenge test, the gold standard, is often difficult to implement in a clinical test, due to unpredictable and severe side reactions. The development of allergen raw materials in allergen diagnosis is undergoing a transition from raw extracts to single components, used in CRD to avoid adverse reactions and unnecessary expenses. Moreover, CRD can predict the severity of disease progression and find cross-reactions of different components, which is of great significance in the diagnosis and treatment of allergies. $7,15,25,26$

Now component resolved diagnostic technologies have recently been introduced into egg white allergen sensitized to slgE, and Gal $d 1$ has been proved to be the major allergen, which is in line with our research, using the AUC from ROC curve analysis. However, there was still a margin in sensitization to egg yolk allergen components: especially if the patient is allergic to only one egg allergen, the patient may not have obvious clinical symptoms. As sensitization to multiple egg allergens, this was more likely to persist. ${ }^{27}$ In our research, nearly $10 \%$ of the specimens sensitized to five proteins, and the cross-reaction frequency between two egg yolk allergens and Gal d 1 was about 30\%. The sensitization mechanisms of Gal d 5 and Gal $d 6$ have been clearly characterized in individuals with egg allergy. From the diagnostic effect of slgE response to single component, we found that Gal $d 1$ had the highest diagnostic value for egg allergy. We knew that the detection of the combinant component was beneficial to improve the clinical diagnostic accuracy, so we used ROC analyses to evaluate the performance of the slgE response of Gal d1 in combination with a single or two egg yolk allergens. All the results showed that the major allergen of egg yolk was Gal d 6, not Gal d 5. Gal d 6 could remain stable after cooking or other heat treatment and it resists the digestion of protease like Gal d 1. Specifically, we found that the combinant component of Gal d 1 with Gal d 6 had the highest diagnostic accuracy.

The limitations of the study were that we did not conduct a SPT on the detected egg yolk allergy samples to verify it. In fact, the evidence of the following study can be obtained by pricking the raw extract of cooked egg yolk and raw egg yolk and one-component protein respectively. SPT and slgE level detection strengthen the diagnostic value of egg allergy. ${ }^{28}$ In particular, these results are of significance for the study of the persistence and the elimination of egg allergy.
There is more increasing evidence that egg allergy is not solely an egg-white allergy but that it also contains egg yolk allergy. Egg yolk allergen component resolve diagnosed, and slgE response to combinations of egg allergen components has not been to be turned back. As far as we know, our study is the first to reveal a clinical experiment for egg yolk allergy in patients who reacted to whole hen's egg from Tianjin, China. Subsequently, our team will analyze and refine egg white allergen with egg yolk allergen diagnosis from resolving antigen epitopes.

\section{References}

1. Lötvall J. We call for iCAALL: international collaboration in asthma, allergy and immunology. World Allerg Organ. 2012;5:39-40. https://doi.org/10.1097/WOX.0b013e3182504245

2. Ansotegui IJ, Melioli G, Canonica GW, Caraballo L, Villa E, Ebisawa $M$, et al. IgE allergy diagnostics and other relevant tests in allergy, a world allergy organization position paper. World Allerg Organ. 2020;13:100080. https://doi.org/10.1016/j. waojou.2019.100080

3. Sicherer SH, Sampson HA. Food allergy: a review and update on epidemiology, pathogenesis, diagnosis, prevention, and management. J Allerg Clin Immunol. 2018;141:41-58. https:// doi.org/10.1016/j.jaci.2017.11.003

4. Walkner M, Warren C, Gupta RS. Quality of life in food allergy patients and their families. Pediatr Clin N Am. 2015;62:1453-61. https://doi.org/10.1016/j.pcl.2015.07.003

5. Berin MC, Sampson HA. Food allergy: an enigmatic epidemic. Trends Immunol. 2013;34:390-7. https://doi.org/10.1016/j.it. 2013.04.003

6. Fleischer DM. Allergic reactions to foods in preschool-aged children in a prospective observational food allergy study. Pediatrics. 2012;130:e25-32. https://doi.org/10.1542/peds.2011-1762

7. Jessadapakorn $W$, Sangsupawanich $P$, Wootipoom N, Suddeaugrai 0 , Yuenyongviwat A. Component-resolved diagnostics in Thai children with cow's milk and egg allergy. Asian Pac J Allerg Immunol. 2017;35:179-85.

8. Roberts $G$, Ollert $M$, Aalberse R, Austin M, Custovic A, DunnGalvin A, et al. A new framework for the interpretation of IgE sensitization tests. Allergy. 2016;71:1540-51. https:// doi.org/10.1111/all.12939

9. Calamelli E, Liotti L, Beghetti I, Piccinno V, Serra L, Bottau P. Component-resolved diagnosis in food allergies. Medicina. 2019;55:498-17. https://doi.org/10.3390/medicina55080498

10. Matricardi PM, Kleine-Tebbe J, Hoffmann HJ, Valenta R, Hilger C, Hofmaier S, et al. EAACI molecular allergology user's guide. Pediatr Allerg Immunol. 2016;27(Suppl 23):1-250. 
11. Lemon-Mulé $H$, Sampson HA, Sicherer SH, Shreffler WG, Noone S, Nowak-Wegrzyn A. Immunologic changes in children with egg allergy ingesting extensively heated egg. J Allerg Clin Immunol. 2008;122:977-83. https://doi.org/10.1016/j. jaci.2008.09.007

12. Haneda YMP, Kando NM, Yasui MM, Kobayashi TM, Maeda TM, Hino AM, et al. Ovomucoids IgE is a better marker than egg white-specific IgE to diagnose boiled egg allergy. J Allerg Clin Immunol. 2012;129:1681-2. https://doi.org/10.1016/j. jaci.2012.03.041

13. Tan JW, Campbell DE, Turner PJ, Kakakios A, Wong M, Mehr S, et al. Baked egg food challenges - clinical utility of skin test to baked egg and ovomucoid in children with egg allergy. Clin Exp Allerg. 2013;43(10):1189-95.

14. Ando H, Movérare R, Kondo Y, Tsuge I, Tanaka A, Borres MP, Urisu A. Utility of ovomucoid-specific IgE concentrations in predicting symptomatic egg allergy. J Allerg Clin Immunol. 2008;122:583-8. https://doi.org/10.1016/j.jaci.2008.06.016

15. De Martinis M, Sirufo MM, Suppa M, Ginaldi L. New perspectives in food allergy. Int J Mol Sci. 2020;21:1474. https://doi. org/10.3390/ijms21041474

16. Okada Y, Yanagida N, Sato S, Ebisawa M. Heated egg yolk challenge predicts the natural course of hen's egg allergy: a retrospective study. Word Allerg Organ. 2016;9:31. https://doi. org/10.1186/s40413-016-0121-4

17. Szepfalusi Z, Ebner C, Pandjaitan R, Orlicek F, Scheiner O, Boltz-Nitulescu G, et al. Egg yolk alpha-livetin (chicken serum albumin) is a cross-reactive allergen in the bird-egg syndrome. J Allerg Clin Immunol. 1994;93:932-42. https://doi. org/10.1016/0091-6749(94)90388-3

18. Amo A, Rodríguez-Pérez $\mathrm{R}$, Blanco J, Villota J, Juste $\mathrm{S}$, Moneo I, et al. Gal d 6 is the second allergen characterized from egg yolk. J Agricult Food Chem. 2010;58:7453-7. https:// doi.org/10.1021/jf101403h

19. De Silva C, Dhanapala P, King S, Doran T, Tang M, Suphioglu C. Immunological comparison of native and recombinant Hen's egg yolk allergen, chicken serum albumin (gal d 5), produced in Kluveromyces lactis. Nutrients. 2018;10:757. https://doi. org/10.3390/nu10060757
20. De Silva C, Dhanapala P, Doran T, Tang MLK, Suphioglu C. Molecular and immunological analysis of Hen's egg yolk allergens with a focus on YGP42 (Gal d 6). J Mol Immunol. 2016;71:152-60. https://doi.org/10.1016/j.molimm.2016.02.005

21. Netting M, Donato A, Makrides M, Gold M, Quinn P, Penttila I. Allergenicity of pasteurized whole raw Hen's egg compared with fresh whole raw Hen's egg. Pediatr Allerg Immunol. 2015;26:234-8. https://doi.org/10.1111/pai.12365

22. Goikoetxea MJ, Sanz ML, Garcia BE, Mayorga C, Longo N, Gamboa PM, et al. Recommendations for the use of in vitro methods to detect specific immunoglobulin E: are they comparable? Investig Allergol Clin Immunol. 2013,23:448-54, 2-455.

23. Drewnowski A. The nutrient rich foods index helps to identify healthy, affordable foods. Am J Clin Nutr. 2010;91:1095S-1S. https://doi.org/10.3945/ajcn.2010.28450D

24. Réhault-Godbert S, Guyot N, Nys Y. The golden egg: nutritional value, bioactivities, and emerging benefits for human health. Nutrients. 2019;11:684. https://doi.org/10.3390/ nu11030684

25. Hoffmann-Sommergruber K, Pfeifer S, Bublin M. Applications of molecular diagnostic testing in food allergy. Curr Allergy Asthma Rep. 2015;15:56-63. https://doi.org/10.1007/ s11882-015-0557-6

26. Del-Río Camacho G, Montes Arjona AM, Fernández-Cantalejo Padial J, Rodríguez Catalán J. How molecular diagnosis may modify immunotherapy prescription in multi-sensitized pollen-allergic children. Allergol Immunopathol. 2018;46:552-6. https://doi.org/10.1016/j.aller.2018.03.002

27. Dang TD, Mills CEN, Allen KJ. Determination of the clinical egg allergy phenotypes using component-resolved diagnostics. Pediatr Allergy Immunol. 2014;25:639-43. https://doi. org/10.1111/pai.12301

28. Nacaroglu HT, Erdem SB, Karaman S, Dogan D, Karkiner CSU, Kanık ET, et al. Diagnostic values for egg white specific IgE levels with the skin prick test in Turkish children with egg white allergy. Allergol Immunopathol. 2017;45:445-51. https:// doi.org/10.1016/j.aller.2016.10.018 


\section{Supporting Information Table S}

Clinical characteristics of the study subjects

\begin{tabular}{|c|c|c|c|c|c|c|c|c|c|}
\hline \multirow{2}{*}{$\begin{array}{l}\text { Subject } \\
\text { Group }\end{array}$} & \multirow{2}{*}{$\begin{array}{l}\text { Subject } \\
\text { no. }\end{array}$} & \multirow{2}{*}{$\begin{array}{c}\text { Age (years)/ } \\
\text { Gender } \\
\text { M/F) }\end{array}$} & \multirow{2}{*}{$\begin{array}{l}\text { CAP to egg } \\
\text { (kUa/L) }\end{array}$} & \multicolumn{6}{|c|}{ ELISA to egg components (OD450) } \\
\hline & & & & Gal d 1 & Gal d 2 & Gal d 3 & Gal d 4 & Gal d 5 & Gal d 6 \\
\hline \multirow[t]{53}{*}{ EWA } & 1 & $0.5 / F$ & 1.20 & 0.304 & 0.526 & 0.519 & 0.213 & 0.318 & 0.611 \\
\hline & 2 & $2.0 / \mathrm{F}$ & 0.85 & 0.509 & 0.447 & 0.430 & 0.225 & 0.412 & 0.148 \\
\hline & 3 & $12.0 / \mathrm{F}$ & 38.00 & 0.434 & 0.696 & 0.361 & 0.222 & 0.220 & 0.469 \\
\hline & 4 & $1.0 / M$ & 0.73 & 0.298 & 0.530 & 0.354 & 0.270 & 0.235 & 0.559 \\
\hline & 5 & $5.0 / \mathrm{M}$ & 0.97 & 0.271 & 0.386 & 0.345 & 0.289 & 0.253 & 0.505 \\
\hline & 6 & $0.4 / F$ & 13.52 & 0.330 & 0.407 & 0.354 & 0.413 & 0.314 & 0.460 \\
\hline & 7 & $1.0 / \mathrm{F}$ & 3.63 & 0.391 & 0.227 & 0.358 & 0.236 & 0.277 & 0.439 \\
\hline & 8 & $1.2 / \mathrm{F}$ & 26.14 & 0.656 & 0.451 & 0.395 & 0.218 & 0.342 & 0.351 \\
\hline & 9 & $2.0 / \mathrm{F}$ & 2.50 & 0.507 & 0.556 & 0.541 & 0.278 & 0.318 & 0.380 \\
\hline & 10 & $7.0 / \mathrm{M}$ & 2.20 & 0.849 & 0.449 & 0.373 & 0.246 & 0.269 & 0.269 \\
\hline & 11 & $2.0 / \mathrm{M}$ & 2.58 & 0.723 & 0.398 & 0.359 & 0.319 & 0.236 & 0.320 \\
\hline & 12 & $0.5 / \mathrm{M}$ & 4.70 & 0.497 & 0.409 & 0.369 & 0.323 & 0.271 & 0.317 \\
\hline & 13 & $1.8 / \mathrm{F}$ & 2.50 & 0.452 & 0.498 & 0.370 & 0.349 & 0.256 & 0.542 \\
\hline & 14 & $10.0 / M$ & 2.88 & 0.550 & 0.890 & 0.317 & 0.324 & 0.123 & 0.655 \\
\hline & 15 & $2.0 / \mathrm{F}$ & 9.00 & 0.652 & 0.579 & 0.319 & 0.252 & 0.277 & 0.460 \\
\hline & 16 & $7.0 / \mathrm{M}$ & 1.40 & 1.094 & 0.544 & 0.403 & 0.153 & 0.193 & 0.451 \\
\hline & 17 & $1.0 / \mathrm{M}$ & 35.00 & 0.931 & 0.732 & 0.524 & 0.405 & 0.260 & 0.449 \\
\hline & 18 & $1.2 / \mathrm{F}$ & 0.78 & 0.839 & 0.495 & 0.407 & 0.329 & 0.182 & 0.478 \\
\hline & 19 & $0.3 / \mathrm{M}$ & 1.22 & 0.726 & 0.345 & 0.355 & 0.464 & 0.274 & 0.183 \\
\hline & 20 & $0.8 / \mathrm{F}$ & 1.40 & 0.724 & 0.389 & 0.371 & 0.292 & 0.238 & 0.135 \\
\hline & 21 & $0.9 / F$ & 3.70 & 0.387 & 0.375 & 0.313 & 0.353 & 0.229 & 0.651 \\
\hline & 22 & $3.1 / F$ & 1.20 & 1.149 & 0.468 & 0.424 & 0.469 & 0.221 & 0.553 \\
\hline & 23 & $3.1 / F$ & 1.10 & 0.911 & 0.325 & 0.382 & 0.481 & 0.124 & 0.217 \\
\hline & 24 & $2.3 / \mathrm{M}$ & 0.55 & 0.868 & 0.391 & 0.366 & 0.354 & 0.365 & 0.190 \\
\hline & 25 & $23.0 / \mathrm{M}$ & 1.71 & 0.729 & 0.562 & 0.546 & 0.267 & 0.173 & 0.115 \\
\hline & 26 & $14.0 / M$ & 23.40 & 0.260 & 0.554 & 0.419 & 0.163 & 0.236 & 0.119 \\
\hline & 27 & $4.0 / M$ & 0.97 & 0.532 & 0.416 & 0.517 & 0.257 & 0.279 & 0.715 \\
\hline & 28 & $5.0 / \mathrm{F}$ & 12.08 & 0.286 & 0.231 & 0.385 & 0.174 & 0.359 & 0.690 \\
\hline & 29 & $2.0 / \mathrm{F}$ & 6.00 & 0.550 & 0.374 & 0.356 & 0.364 & 0.193 & 0.113 \\
\hline & 30 & $2.3 / \mathrm{F}$ & 2.30 & 0.745 & 0.253 & 0.298 & 0.231 & 0.241 & 0.148 \\
\hline & 31 & $6.4 / F$ & 3.70 & 0.808 & 0.285 & 0.400 & 0.117 & 0.281 & 0.456 \\
\hline & 32 & $0.8 / \mathrm{M}$ & 3.63 & 0.519 & 0.314 & 0.653 & 0.241 & 0.327 & 0.241 \\
\hline & 33 & $1.2 / \mathrm{F}$ & 12.50 & 0.311 & 0.523 & 0.498 & 0.155 & 0.216 & 0.163 \\
\hline & 34 & $12.0 / \mathrm{F}$ & 1.27 & 0.962 & 0.328 & 0.450 & 0.182 & 0.202 & 0.256 \\
\hline & 35 & $2.2 / \mathrm{F}$ & 6.54 & 0.977 & 0.462 & 0.469 & 0.248 & 0.255 & 0.247 \\
\hline & 36 & $1.8 / \mathrm{F}$ & 9.40 & 0.342 & 0.443 & 0.527 & 0.256 & 0.261 & 0.138 \\
\hline & 37 & $2.3 / \mathrm{M}$ & 12.10 & 0.669 & 0.278 & 0.511 & 0.368 & 0.329 & 0.197 \\
\hline & 38 & $3.0 / \mathrm{M}$ & 17.18 & 0.388 & 0.529 & 0.487 & 0.274 & 0.269 & 0.262 \\
\hline & 39 & $3.1 / \mathrm{F}$ & 2.63 & 0.313 & 0.317 & 0.423 & 0.256 & 0.334 & 0.141 \\
\hline & 40 & $0.3 / \mathrm{M}$ & 3.10 & 0.489 & 0.306 & 0.841 & 0.419 & 0.461 & 0.162 \\
\hline & 41 & $2.8 / \mathrm{M}$ & 2.94 & 0.820 & 0.390 & 0.571 & 0.269 & 0.346 & 0.196 \\
\hline & 42 & $2.0 / \mathrm{F}$ & 7.00 & 0.302 & 0.236 & 0.553 & 0.167 & 0.312 & 0.143 \\
\hline & 43 & $1.0 / \mathrm{F}$ & 15.60 & 0.780 & 0.349 & 0.556 & 0.225 & 0.280 & 0.199 \\
\hline & 44 & $1.9 / M$ & 12.08 & 0.764 & 0.454 & 0.507 & 0.286 & 0.288 & 0.229 \\
\hline & 45 & $2.0 / \mathrm{F}$ & 2.48 & 1.221 & 0.519 & 0.742 & 0.235 & 0.329 & 0.115 \\
\hline & 46 & $12.0 / \mathrm{M}$ & 2.68 & 0.753 & 0.218 & 0.776 & 0.268 & 0.331 & 0.217 \\
\hline & 47 & 7.0/M & 23.15 & 0.453 & 0.344 & 0.467 & 0.440 & 1.172 & 0.143 \\
\hline & 48 & $5.0 / \mathrm{F}$ & 55.62 & 1.192 & 0.425 & 0.258 & 0.217 & 1.055 & 0.198 \\
\hline & 49 & $3.0 / F$ & 11.21 & 0.636 & 0.296 & 0.143 & 0.194 & 0.983 & 0.172 \\
\hline & 50 & $3.0 / F$ & 14.45 & 0.560 & 0.433 & 0.110 & 0.259 & 0.438 & 0.245 \\
\hline & 51 & $3.0 / \mathrm{M}$ & 1.20 & 0.679 & 0.304 & 0.108 & 0.334 & 1.001 & 0.159 \\
\hline & 52 & $2.0 / \mathrm{M}$ & 9.55 & 0.922 & 0.362 & 0.199 & 0.284 & 0.866 & 0.134 \\
\hline & 53 & $4.0 / F$ & 10.07 & 0.879 & 0.386 & 0.308 & 0.214 & 0.423 & 0.141 \\
\hline
\end{tabular}


Clinical characteristics of the study subjects (continued)

\begin{tabular}{|c|c|c|c|c|c|c|c|c|c|}
\hline \multirow{2}{*}{$\begin{array}{l}\text { Subject } \\
\text { Group }\end{array}$} & \multirow{2}{*}{$\begin{array}{c}\text { Subject } \\
\text { no. }\end{array}$} & \multirow{2}{*}{$\begin{array}{c}\text { Age(years)/ } \\
\text { Gender } \\
\text { M/F) }\end{array}$} & \multirow{2}{*}{$\begin{array}{l}\text { CAP to egg } \\
(\mathrm{kUa} / \mathrm{L})\end{array}$} & \multicolumn{6}{|c|}{ ELISA to egg components (OD450) } \\
\hline & & & & Gal d 1 & Gal d 2 & Gal d 3 & Gal d 4 & Gal d 5 & Gal d 6 \\
\hline & 54 & $4.0 / F$ & 14.45 & 1.058 & 0.296 & 0.409 & 0.188 & 1.138 & 0.154 \\
\hline & 55 & $5.0 / \mathrm{M}$ & 5.50 & 0.401 & 0.266 & 0.225 & 0.197 & 1.186 & 0.114 \\
\hline & 56 & $1.0 / \mathrm{F}$ & 64.63 & 0.403 & 0.217 & 0.217 & 0.208 & 1.077 & 0.494 \\
\hline & 57 & $1.3 / \mathrm{F}$ & 6.70 & 0.306 & 0.386 & 0.178 & 0.250 & 1.063 & 0.511 \\
\hline & 58 & $1.2 / \mathrm{M}$ & 15.60 & 0.483 & 0.389 & 0.229 & 0.191 & 0.738 & 0.501 \\
\hline & 59 & $4.0 / \mathrm{M}$ & 27.60 & 0.557 & 0.389 & 0.223 & 0.221 & 0.364 & 0.377 \\
\hline & 60 & $1.0 / \mathrm{F}$ & 19.03 & 0.406 & 0.389 & 0.182 & 0.235 & 0.348 & 0.354 \\
\hline & 61 & $3.0 / \mathrm{F}$ & 2.20 & 0.930 & 0.390 & 0.179 & 0.228 & 0.378 & 0.403 \\
\hline & 62 & $0.7 / \mathrm{F}$ & 1.27 & 0.588 & 0.441 & 0.373 & 0.244 & 0.239 & 0.392 \\
\hline & 63 & $15.0 / \mathrm{F}$ & 73.11 & 0.277 & 0.404 & 0.391 & 0.163 & 0.430 & 0.332 \\
\hline & 64 & $22.0 / F$ & 10.87 & 0.284 & 0.306 & 0.221 & 0.153 & 0.334 & 0.449 \\
\hline & 65 & $9.0 / \mathrm{F}$ & 3.30 & 0.589 & 0.453 & 0.209 & 0.226 & 0.312 & 0.509 \\
\hline & 66 & $2.0 / \mathrm{M}$ & 2.60 & 0.586 & 0.359 & 0.159 & 0.163 & 0.516 & 0.494 \\
\hline & 67 & $0.5 / \mathrm{M}$ & 1.93 & 0.640 & 0.309 & 0.188 & 0.225 & 0.251 & 0.492 \\
\hline & 68 & $1.0 / \mathrm{M}$ & 1.27 & 0.712 & 0.391 & 0.393 & 0.195 & 0.315 & 0.501 \\
\hline & 69 & $0.8 / \mathrm{M}$ & 5.30 & 0.781 & 0.254 & 0.475 & 0.192 & 0.764 & 0.601 \\
\hline & 70 & $42.0 / F$ & 31.00 & 0.874 & 0.362 & 0.249 & 0.206 & 0.325 & 0.637 \\
\hline & 71 & $3.0 / \mathrm{M}$ & 42.11 & 0.974 & 0.224 & 0.228 & 0.162 & 0.673 & 0.616 \\
\hline & 72 & $1.0 / \mathrm{F}$ & 2.60 & 0.915 & 0.347 & 0.235 & 0.171 & 0.759 & 0.640 \\
\hline & 73 & $3.0 / \mathrm{M}$ & 6.00 & 1.174 & 0.270 & 0.194 & 0.175 & 1.083 & 0.567 \\
\hline & 74 & $2.0 / \mathrm{M}$ & 23.40 & 0.722 & 0.309 & 0.228 & 0.151 & 0.297 & 0.263 \\
\hline & 75 & $3.0 / \mathrm{F}$ & 3.86 & 0.986 & 0.387 & 0.258 & 0.175 & 0.238 & 0.240 \\
\hline & 76 & $2.3 / \mathrm{F}$ & 2.88 & 0.639 & 0.350 & 0.581 & 0.166 & 0.390 & 0.272 \\
\hline & 77 & $5.0 / \mathrm{M}$ & 3.10 & 0.651 & 0.552 & 0.319 & 0.174 & 0.526 & 0.238 \\
\hline & 78 & $5.0 / \mathrm{M}$ & 22.50 & 0.774 & 0.185 & 0.237 & 0.196 & 0.285 & 0.248 \\
\hline & 79 & $1.0 / \mathrm{M}$ & 15.80 & 1.371 & 0.189 & 0.353 & 0.196 & 0.285 & 0.244 \\
\hline & 80 & $5.0 / \mathrm{F}$ & 71.00 & 1.334 & 0.287 & 0.209 & 0.163 & 0.344 & 0.263 \\
\hline & 81 & $0.1 / F$ & 7.27 & 0.902 & 0.345 & 0.232 & 0.178 & 0.314 & 0.258 \\
\hline & 82 & $25.0 / M$ & 6.50 & 0.480 & 0.309 & 0.285 & 0.200 & 0.235 & 0.233 \\
\hline & 83 & $2.0 / \mathrm{M}$ & 13.90 & 1.075 & 0.292 & 0.352 & 0.299 & 0.147 & 0.225 \\
\hline & 84 & $0.2 / \mathrm{F}$ & 10.87 & 0.823 & 0.272 & 0.207 & 0.377 & 0.213 & 0.244 \\
\hline & 85 & $1.0 / \mathrm{F}$ & 14.00 & 0.798 & 0.260 & 0.212 & 0.330 & 0.148 & 0.236 \\
\hline & 86 & $1.8 / \mathrm{M}$ & 15.60 & 0.997 & 0.257 & 0.219 & 0.309 & 0.174 & 0.253 \\
\hline & 87 & $3.0 / \mathrm{M}$ & 8.00 & 0.715 & 0.188 & 0.243 & 0.339 & 0.210 & 0.261 \\
\hline & 88 & $3.0 / \mathrm{F}$ & 7.11 & 1.093 & 0.392 & 0.204 & 0.387 & 0.116 & 0.256 \\
\hline & 89 & $2.0 / \mathrm{F}$ & 11.40 & 1.161 & 0.400 & 0.296 & 0.243 & 0.125 & 0.273 \\
\hline & 90 & $1.0 / M$ & 5.10 & 0.691 & 0.223 & 0.186 & 0.278 & 0.183 & 0.253 \\
\hline & 91 & $15.0 / M$ & 17.60 & 0.767 & 0.228 & 0.193 & 0.269 & 0.123 & 0.249 \\
\hline & 92 & $7.0 / \mathrm{F}$ & 17.40 & 0.594 & 0.258 & 0.184 & 0.321 & 0.160 & 0.249 \\
\hline & 93 & $5.0 / \mathrm{F}$ & 13.22 & 0.474 & 0.239 & 0.170 & 0.261 & 0.178 & 0.216 \\
\hline & 94 & $14.0 / M$ & 0.83 & 0.423 & 0.241 & 0.206 & 0.388 & 0.118 & 0.215 \\
\hline & 95 & $3.0 / \mathrm{F}$ & 43.40 & 0.733 & 0.193 & 0.205 & 0.313 & 0.154 & 0.215 \\
\hline & 96 & $3.5 / F$ & 12.08 & 0.730 & 0.326 & 0.204 & 0.353 & 0.168 & 0.235 \\
\hline & 97 & $0.2 / F$ & 3.41 & 0.835 & 0.254 & 0.125 & 0.306 & 0.142 & 0.217 \\
\hline & 98 & $1.0 / M$ & 0.37 & 0.342 & 0.269 & 0.087 & 0.421 & 0.213 & 0.417 \\
\hline & 99 & $10.0 / M$ & 0.82 & 0.371 & 0.186 & 0.089 & 0.339 & 0.193 & 0.329 \\
\hline \multicolumn{10}{|c|}{ Non-EWA } \\
\hline & 100 & $1.0 / \mathrm{M}$ & $<0.35$ & 0.333 & 0.198 & 0.324 & 0.193 & 0.300 & 0.259 \\
\hline & 101 & $2.3 / \mathrm{F}$ & $<0.35$ & 0.120 & 0.223 & 0.220 & 0.206 & 0.304 & 0.142 \\
\hline & 102 & $0.5 / F$ & $<0.35$ & 0.164 & 0.154 & 0.147 & 0.225 & 1.195 & 0.272 \\
\hline & 103 & $1.8 / \mathrm{M}$ & $<0.35$ & 0.234 & 0.204 & 0.191 & 0.165 & 1.273 & 0.447 \\
\hline & 104 & $2.0 / \mathrm{M}$ & $<0.35$ & 0.182 & 0.237 & 0.155 & 0.204 & 0.400 & 0.206 \\
\hline & 105 & $5.0 / \mathrm{F}$ & $<0.35$ & 0.249 & 0.230 & 0.185 & 0.191 & 0.314 & 0.468 \\
\hline & 106 & $1.0 / \mathrm{F}$ & $<0.35$ & 0.349 & 0.252 & 0.214 & 0.248 & 0.516 & 0.139 \\
\hline & 107 & $9.0 / \mathrm{F}$ & $<0.35$ & 0.280 & 0.213 & 0.221 & 0.197 & 1.329 & 0.366 \\
\hline
\end{tabular}


Clinical characteristics of the study subjects

\begin{tabular}{|c|c|c|c|c|c|c|c|c|c|}
\hline \multirow{2}{*}{$\begin{array}{l}\text { Subject } \\
\text { Group }\end{array}$} & \multirow{2}{*}{$\begin{array}{c}\text { Subject } \\
\text { no. }\end{array}$} & \multirow{2}{*}{$\begin{array}{c}\text { Age(years)/ } \\
\text { Gender } \\
\text { M/F) }\end{array}$} & \multirow{2}{*}{$\begin{array}{l}\text { CAP to egg } \\
(\mathrm{kUa} / \mathrm{L})\end{array}$} & \multicolumn{6}{|c|}{ ELISA to egg components (OD450) } \\
\hline & & & & Gal d 1 & Gal d 2 & Gal d 3 & Gal d 4 & Gal d 5 & Gal d 6 \\
\hline & 108 & $24.0 / M$ & $<0.35$ & 0.268 & 0.205 & 0.211 & 0.179 & 0.328 & 0.363 \\
\hline & 109 & $1.0 / M$ & $<0.35$ & 0.290 & 0.266 & 0.135 & 0.253 & 0.217 & 0.204 \\
\hline & 110 & $0.5 / M$ & $<0.35$ & 0.241 & 0.258 & 0.195 & 0.204 & 0.474 & 0.384 \\
\hline & 111 & $2.0 / \mathrm{F}$ & $<0.35$ & 0.342 & 0.267 & 0.168 & 0.199 & 0.483 & 0.404 \\
\hline & 112 & $2.0 / \mathrm{M}$ & $<0.35$ & 0.156 & 0.161 & 0.221 & 0.184 & 0.232 & 0.219 \\
\hline & 113 & $1.0 / M$ & $<0.35$ & 0.152 & 0.372 & 0.244 & 0.159 & 0.251 & 0.167 \\
\hline & 114 & $29.0 / F$ & $<0.35$ & 0.133 & 0.189 & 0.198 & 0.202 & 0.134 & 0.254 \\
\hline & 115 & $7.0 / \mathrm{F}$ & $<0.35$ & 0.138 & 0.224 & 0.219 & 0.159 & 0.185 & 0.295 \\
\hline & 116 & $1.0 / \mathrm{F}$ & $<0.35$ & 0.105 & 0.176 & 0.079 & 0.252 & 0.240 & 0.309 \\
\hline & 117 & $2.0 / F$ & $<0.35$ & 0.104 & 0.144 & 0.055 & 0.149 & 0.273 & 0.125 \\
\hline & 118 & $19.0 / \mathrm{F}$ & $<0.35$ & 0.222 & 0.185 & 0.105 & 0.235 & 0.242 & 0.200 \\
\hline & 119 & $3.0 / \mathrm{M}$ & $<0.35$ & 0.114 & 0.217 & 0.103 & 0.141 & 0.179 & 0.269 \\
\hline & 120 & $1.5 / M$ & $<0.35$ & 0.173 & 0.241 & 0.129 & 0.205 & 0.163 & 0.289 \\
\hline
\end{tabular}

